\title{
SCREENING OF MICROBIAL LIPASES AND EVALUATION OF THEIR POTENTIAL TO PRODUCE GLYCERIDES WITH HIGH GAMMA LINOLENIC ACID CONCENTRATION
}

\author{
Patricia B.L. Fregolente ${ }^{1}$, Leonardo V. Fregolente ${ }^{1}$, Maria R.W. Maciel ${ }^{1}$, Patricia O. Carvalho ${ }^{2 *}$ \\ ${ }^{1}$ Universidade Estadual de Campinas, Faculdade de Engenharia Química, Departamento de Processos Químicos, Campinas, \\ SP, Brasil; ${ }^{2}$ Universidade São Francisco, Laboratório de Biotecnologia, Bragança Paulista, SP, Brasil.
}

Submitted: June 03, 2008; Returned to authors for corrections: August 27, 2008; Approved: May 19, 2009.

\begin{abstract}
Gamma-linolenic acid (GLA, 18:3, cis- 6,9,12-octadecatrienoic acid), an important compound in n-6 eicosanoid family biosynthesis, occurs in the lipids of a few plant and microbial sources. This study focused on the screening of microbial strains with suitable lipase activity for enrichment of GLA by selective hydrolysis of the borage oil (21.6\% of GLA/total fatty acids). Firstly, 352 microrganisms were tested for their lipolytic capacity using screening techniques on agar plates containing borage oil, strains were then selected and screened for their activity $(\mathrm{U} / \mathrm{mg})$ using both submerged fermentation $(\mathrm{SmF})$ and solid state fermentation (SSF). The rate of hydrolysis and the selective preference of these hydrolytic enzymes towards fatty acids, with a special focus on enrichment of GLA were studied and compared with those obtained by two commercially-available lipases. Only one of the lipases tested during this study displayed selectivity, discriminating the GLA during the hydrolysis reaction. Using the enzymatic extract from Geotrichum candidum as a biocatalyst of the reaction, it was possible to obtain a percentage of $41.7 \%$ of GLA in acylglycerols fraction when the borage oil was treated in a fixed-bed reactor for 24 hours at $30^{\circ} \mathrm{C}$.
\end{abstract}

Key words: gamma linolenic acid, borage oil, lipase, Geotrichum candidum

\section{INTRODUCTION}

Polyunsaturated fatty acids (PUFA) present important actions in physiological functions, therefore intensive efforts have been made to identify the possible effects of eicosapentaenoic acid (EPA), docosahexaenoic (DHA) and gamma-linolenic acid (GLA) in treating some diseases. GLA has been reported to be an effective nutritional supplement to treat premenstrual syndrome (2), cancer (3), certain skin diseases (11) and hypertriglycemidemia (18). Several studies have demonstrated a significant role of the dietary ômega-6 PUFA in hypertension treatment (10). Some processes have been developed for the concentration of these fatty acids to incorporate them in food supplies, since higher animals are unable to synthesize all the fatty acids they need and the dosages necessary to reach the desired biological effect would demand the ingestion of a great amount of oils in their natural forms. Urea complexation (19), low temperature

*Corresponding Author. Mailing address: Universidade São Francisco, Av. São Francisco de Assis, 218 CEP 12916-900, Bragança Paulista, SP, Brasil.; Tel: 5511 2454-8298.; E-mail: patcarvalho@saofrancisco.edu.br 
crystallization (7) and supercritical extraction (32) are some optional methods for the enrichment of GLA. However, lipase-catalyzed reactions are an advantageous alternative for this objective since, owing to the high selectivity of some lipases toward unsaturated fatty acids, PUFA can be concentrated in the remaining acylglycerols, with consequent nutritional advantages (6).

In particular, three plants have become important sources of GLA: borage (Borago officinalis), evening primrose (Oenothera biennis) and blackcurrant (Ribes nigrum). These natural sources generally contain variable quantities of GLA (31), rarely exceeding $25 \%$ of GLA in the oil (e.g. borage oil).

Among the high numbers of lipases described in the literature, only the enzymes belonging to a few species have been demonstrated to have adequate stability and selectivity to allow routine use for the concentration of PUFA. Some researchers have reported that lipases from Candida species are effective for the enrichment of PUFA via selective hydrolysis $(27,13,28,29,22)$. Few studies have been carried out to exploit the capacities of novel microbial lipases to concentrate the content of PUFA in oils $(12,21,25)$. In a preliminary study, we reported that some native lipases provide good results for the concentration of GLA from a fungal oil derived from Mucor sp (4).

In this present study, we describe the selection, by screening techniques, of lipase-producing microrganisms and the preliminary characterization of the catalytic performance of native lipase preparations to concentrate the content of GLA in the acylglycerols fraction in borage oil by selective hydrolysis in a fixed-bed reactor. We used lipase-producing microrganisms, isolated from natural sources, and compared their lipases with commercially-available lipases from Candida cylindracea and Aspergillus niger as biocatalysts. In addition, a preliminary study with respect to the influence of growing media, enzyme concentration and time reaction in the concentration of GLA in the borage oil of selected lipase was carried out.

\section{MATERIALS AND METHODS}

\section{Chemicals}

Yeast extract and Bacto peptone were purchased from Difco Laboratories, (Detroit, MI, USA). The components from culture media, chemical reagents and the other solvents were obtained from Merck (Darmstadt, Germany) and from Sigma-Aldrich Chemical Co. in the highest purity available. The Borage oil was purchased from SP Farma Ltda (São Paulo, Brazil). The commercial lipases employed were Candida cylindracea (Sigma - -Aldrich Co. St. Louis, MO) and Aspergilus niger (Aldrich Chemical Company, Inc., Milwaukee, WI). Low acidity olive oil (Carbonel) and wheat flour were purchased at a local market.

\section{Isolation and preliminary screening of lipase-producing microrganisms}

All the microrganisms used in this study were isolated from soil and fruit samples and collected from Southwest Brazil. The samples were suspended in a buffer $(0.85 \%$ saline solution) and the isolation process was performed by serial dilution of the samples, according to standard techniques (16). Preliminary screening of lipolytic filamentous fungi and yeast was carried out on BYPO agar plates supplemented with a $10 \%(\mathrm{v} / \mathrm{v})$ borage oil emulsion prepared in $10 \%(\mathrm{w} / \mathrm{v})$ Arabic gum solution. Culture plates were incubated at $30^{\circ} \mathrm{C}$ and periodically examined for 4 days. Colonies showing clear zones around them were picked out and used for lipase production.

\section{Lipase production}

The production of lipase was studied using both submerged fermentation $(\mathrm{SmF})$ and solid state fermentation (SSF). The SmF was carried out in a basal medium, with an initial $\mathrm{pH}$ value of 6.0 , consisting of $1 \%$ glucose, $2 \%$ peptone, $0.5 \%$ yeast extract, $0.1 \% \mathrm{NaNO}_{3}, 0.1 \%, \mathrm{KH}_{2} \mathrm{PO}_{4}$, $0.05 \% \mathrm{MgSO}_{4} \cdot 7 \mathrm{H}_{2} \mathrm{O}$ and $1 \%$ olive oil. The cultures were grown in Erlenmeyer flasks $(500 \mathrm{~mL})$ containing $120 \mathrm{~mL}$ of the growth medium and the flasks were agitated by a rotary 
shaker $(130-150 \mathrm{rpm})$ at $30^{\circ} \mathrm{C}$ for $72 \mathrm{~h}$. The lipase production in SSF was carried out in a medium containing 10 $\mathrm{g}$ of wheat flour ( $40 \%$ water w/w) moistened with $10 \mathrm{~mL}$ of the liquid medium described above. The Erlenmeyer flasks $(500 \mathrm{~mL})$ were incubated at $30^{\circ} \mathrm{C}$ for $96 \mathrm{~h}$. After SSF, $100 \mathrm{~mL}$ of aqueous solution of $\mathrm{NaCl}(1 \%)$ was added to each flask and the mixture shaken on a rotary shaker $(180 \mathrm{rpm})$ for $2 \mathrm{~h}$ at room temperature for extraction of enzyme. Both culture broths were collected, centrifuged (3000 rev/min for $15 \mathrm{~min}$.) and the supernatants treated with ammonium sulphate $(80 \%$ saturation). The precipitates were dialyzed overnight against the phosphate buffer $\mathrm{pH}$ 7.0, lyophilized and the resultant powder was used as crude enzyme preparation.

\section{Identification of the isolates}

Morphological identification of isolates to the species level was accomplished using established procedures (8) and the taxonomic identification was performed by the Centro de Micologia da Universidade de Lisboa, Portugal.

\section{Lipase-catalyzed hydrolysis of the borage oil}

The conditions used for the enzymatic hydrolysis reaction were: $12 \mathrm{~g}$ of Borage oil (22.1\% of GLA), $28 \mathrm{~g}$ of distilled water, $300 \mathrm{U}$ of enzyme /g of oil, stirring at $500 \mathrm{rpm}$ and a temperature of $30^{\circ} \mathrm{C}$. The reaction was conducted using a fixed-bed reactor of $70 \mathrm{~mL}$ and, to interrupt the reaction, the enzyme was deactivated by heating the reaction to approximately $90^{\circ} \mathrm{C}$ for $15 \mathrm{~min}$. All of the lipases selected (native and commercial) were used in the enzymatic hydrolysis reactions fixing a total time of reaction of 24 hours to verify which present a higher enrichment of GLA.

\section{Assay of lipase activity}

Lipolytic activity was determined at $35^{\circ} \mathrm{C}, \mathrm{pH} 7.0$, by the titration of free fatty acids with $0.1 \mathrm{~N} \mathrm{NaOH}$ released from olive oil hydrolysis and the quantitation was carried out with a standard oleic acid curve. The enzymatic activity (U) was expressed as micromoles of acid released per minute and milligrams of crude lipase preparation $\left(\mu \mathrm{mol} \mathrm{min} \mathrm{mg}^{-1}\right)$. All experiments were performed with duplicate flasks, with the results reported as the mean of the duplicates.

\section{Separation of the free fatty acids and acylglycerols}

At the end of each enzymatic reaction, acylglycerols (triacylglycerol (TG), diacylglycerol (DG) and monoacylglycerol (MG)) and free fatty acids (FFA) fractions were separated according to a modified procedure outlined in previous study (23). Ten $\mathrm{mg}$ of the reaction mixture were then mixed with $70 \mathrm{~mL}$ of $\mathrm{KOH}$ solution $0.5 \mathrm{~N}$ (30\% ethanol) and the acylglycerols were extracted with $10 \mathrm{~mL}$ of $\mathrm{n}$-hexane. $\mathrm{pH}$ was then returned to acid $\mathrm{pH}$ ( $\mathrm{pH}$ above 2 ) by adding $4 \mathrm{~N}$ $\mathrm{HCl}$. The fatty acids present in the aqueous phase were then extracted by adding $100 \mathrm{~mL}$ of $\mathrm{n}$-hexane and separated by evaporation.

\section{Fatty acid composition analysis}

Both acylglycerols and FFA were converted to methyl esters by treatment with methanol- $\mathrm{BF}_{3}$ as described by AOCS (30) and analyzed by gas chromatography in a Chrompack CG instrument equipped with flame ionization detector (FID). The separations were carried out on a fused silica WCOT CP-Sil 88 capillary column (Chrompack, Holland) using a programmed temperature of $180-220^{\circ} \mathrm{C}, 5^{\circ} \mathrm{C} / \mathrm{min}$. Hydrogen was used as a carrier gas. The composition of fatty acids was identified by comparing retention times with authentic standards (Sigma Chemical Co.) and determined by relative percentage.

\section{Acylglycerols and FFA analysis}

Gel-permeation chromatography, also called highperformance size-exclusion chromatography (HPSEC) was used for the acylglycerols and FFA analyses. The chromatographic system consists of an isocratic pump, model 515 HPLC Pump (Waters, Milford, MA), a differential refractometer detector model 2410 (Waters, Milford, MA), and an oven for columns thermostatted at $40^{\circ} \mathrm{C}$ by a temperature control module (Waters, Milford, MA). The samples were injected using a manual injector, rheodyne 
$7725 \mathrm{i}$ model, with a $20 \mu \mathrm{L}$-sample loop. The mobile phase used was HPLC-grade tetrahydrofuran from Tedia Inc. (Fairfield, $\mathrm{OH}$ ) and the flow rate was $1 \mathrm{~mL} / \mathrm{min}$.

\section{RESULTS AND DISCUSSION}

The screening process and the hydrolytic activity of the lipase preparations selected are shown in Table 1. Microrganisms (352) isolated from soil and fruits samples, including yeasts (48) and filamentous fungi (304) were employed in this work. A total of 23 microrganisms produced a clear halo around them in plates containing borage oil, thus indicating a predominant presence of lipases acting on long chain triglycerides. These strains, selected in the first step, were then cultured in SmF and SSF and were used to quantify their lipase activity using the standard method of titrating fatty acids liberated from olive oil. From this analysis, 5 strains were selected demonstrating the best lipase yields (lipase activity higher than $1 \mathrm{U} / \mathrm{mg}$ of enzyme for one or for both medium cultures). The strains produced were taxonomically identified as follows: Aspergillus niger, Fusarium oxysporum, Geotrichum candidum, Penicillium solitum and Rhizopus javanicus. A. niger, G. candidum and R. javanicus are well known as lipase producers (20). F. oxysporum have also been previously found to have lipolytic activity in solid and in liquid media $(15,9)$. To our knowledge, this is the first report of Penicillium solitum as a lipase producer. Low growth of these strains was observed when SSF was used, explaining the lower values of enzyme activity in the presence of wheat flour than those obtained with liquid culture $(\mathrm{SmF})$.

Table 1. Number of microorganisms selected in this study through the screening process and lipolytic activity of the crude enzymatic extracts using olive oil.

\begin{tabular}{|c|c|c|}
\hline Screening step & Number of sele & rganisms \\
\hline Soil and fruit sample isolation & \multicolumn{2}{|c|}{352} \\
\hline Solid medium screening ${ }^{\text {(a) }}$ & \multicolumn{2}{|c|}{23} \\
\hline Submerged and solid state fermentation ( $\mathrm{SmF}$ and SSF) & \multicolumn{2}{|c|}{5} \\
\hline \multirow[t]{2}{*}{ Sources of lipases } & \multicolumn{2}{|c|}{ Lipase activity (U/mg) ${ }^{(b)}$} \\
\hline & $\mathrm{SmF}^{(\mathrm{c})}$ & SSF $^{\text {(d) }}$ \\
\hline Aspergillus niger & $5.96 \pm 0.23$ & $2.84 \pm 0.29$ \\
\hline Fusarium oxysporum & $4.89 \pm 0.12$ & $4.67 \pm 0.09$ \\
\hline Geotrichum candidum & $4.32 \pm 0.24$ & $2.21 \pm 0.22$ \\
\hline Penicillium solitum & $1.34 \pm 0.07$ & $0.63 \pm 0.21$ \\
\hline Rhizopus javanicus & $1.89 \pm 0.05$ & $0.74 \pm 0.12$ \\
\hline
\end{tabular}

Twenty-five percent of the tested microrganisms produced detectable levels of lipase; this percentage of lipaseproducing species may be regarded as high. Nevertheless, few studies have been carried out to exploit the capacities of these native microbial lipases for enrichment of PUFA by selective hydrolysis of unsaturated oil. To concentrate a specific fatty acid by selective hydrolysis, it is necessary to select lipases that act slightly on the ester of that 
fatty acid, i.e., if there is a lipase that does not hydrolyse GLA esters, GLA will be concentrated in glycerides by hydrolyzing GLA containing oil with this lipase.

Lipases from different sources demonstrate different substrate specificities such as fatty acid (typoselectivity), position (regioselectivity) and stereospecificity. Most of the lipases are classified into two groups: sn-1,3 regiospecific, which mediate selective reactions at the positions sn-1 and sn-3 of the glycerol and glyceride system (e.g. lipases from $A$. niger and $R$. javanicus) and non-regiospecific lipases, which act on all three positions of triacylglycerol (e.g. lipases from C. cylindracea and G. candidum (20). G. candidum produces a lipase that demonstrates pronounced specificity for the hydrolysis of esters of a particular type of long-chain fatty acid with a cis double bond at C9 (14).

In the next experiment, we compared the properties of these native enzyme preparations with those of two commercially available lipases, Candida cylindracea (Sigma) and Aspergilus niger (Aldrich), since the lipase from Candida cylindracea has been found to be suitable for PUFA concentration in glycerides by the hydrolysis reaction $(27$, 17). During the enzymatic hydrolysis reaction of the borage oil by the selective lipases, the concentrations of the TG, DG, MG and FFA were monitored. Figure 1 shows the acylglycerols and FFA contents after $24 \mathrm{~h}$ incubation for each lipase employed in the hydrolysis reaction.

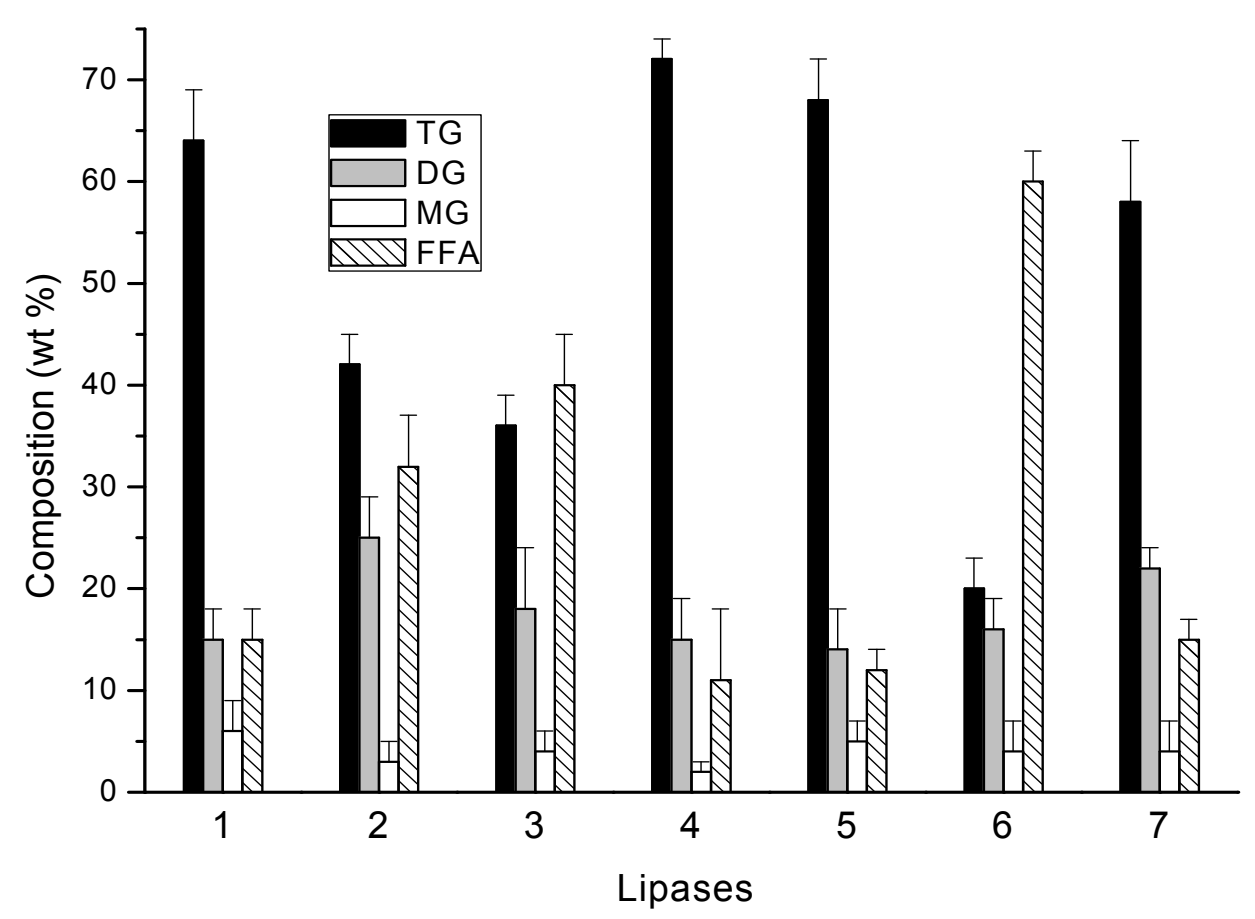

Figure 1. Content of the acylglycerols (TG, DG and MG) and FFA, derived by hydrolysis of borage oil with selected lipases. 1. A. niger, 2. F oxysporum, 3. G. candidum, 4. P. solitum, 5. R. javanicus, 6. C. cylindracea (Sigma), 7. A. niger (Aldrich). Reaction conditions are described in Materials and Methods

As expected, the commercial C. cylindracea lipase presented a high potential to hydrolyze the acylglycerols, obtaining a maximum of $60 \%$ of FFA. Efficient results were also obtained with native $G$. candidum and $F$. oxysporum 
Fregolente, P.B.L. et al.

lipases used as biocatalysts (40 and $32 \%$ of FFA, respectively). Poor results (less than $15 \%$ of FFA) were obtained with the lipases from A. niger (commercial and native), $P$. solitum and $R$. javanicus. The ability of the lipases to hydrolysis borage oil was higher for non-specific lipases (commercial $C$. cylindracea and native $G$. candidum), compared to 1,3-specific lipases (A. niger and $R$. javanicus), which is in agreement with other studies $(5,17)$.

The compositions of the individual fatty acids in the acylglycerols (TG, DG and MG were analyzed as the only collective fraction) and FFA fractions are summarized in Table 2.

Table 2. Fatty acid composition (\%) in the acylglycerols and FFA fractions derived by hydrolysis of borage oil with native and commercial lipases.

\begin{tabular}{|c|c|c|c|c|c|c|c|c|c|}
\hline & \multicolumn{9}{|c|}{ Fatty acid composition (\%) in acylglycerols fraction ${ }^{\text {(a) }}$} \\
\hline & 16:0 & 18:0 & $18: 1$ & $18: 2$ & $18: 3$ & 20:0 & $20: 1$ & $24: 0$ & $\begin{array}{c}\text { Enrichment } \\
\text { of GLA }\end{array}$ \\
\hline Original oil & 12.8 & 4.7 & 17.5 & 36.6 & 21.5 & 0.4 & 4.6 & 1.8 & --- \\
\hline \multicolumn{10}{|c|}{ Native lipases $^{(b)}$} \\
\hline Aspergillus niger & 10.5 & 4.1 & 13.3 & 37.1 & 29.7 & 0.3 & 3.3 & 1.7 & 1.4 \\
\hline Fusarium oxysporum & 7.9 & 3.8 & 15.6 & 35.4 & 30.8 & 0.4 & 4.5 & 1.6 & 1.4 \\
\hline Geotrichum candidum & 5.1 & 2.7 & 12.7 & 37.1 & 39.5 & 0.2 & 2.3 & 1.4 & 1.8 \\
\hline Penicillium solitum & 15.2 & 7.5 & 15.9 & 33.1 & 20.4 & 0.5 & 4.9 & 2.5 & --- \\
\hline Rhizopus javanicus & 11.8 & 4.8 & 17.4 & 36.8 & 22.3 & 0.6 & 4.4 & 1.9 & --- \\
\hline \multicolumn{10}{|c|}{ Commercial lipases } \\
\hline Aspergillus niger & 6.7 & 3.3 & 14.7 & 36.3 & 32.4 & 0.2 & 4.6 & 1.5 & 1.5 \\
\hline \multirow[t]{3}{*}{ Candida cylindracea } & 6.4 & 3.2 & 15.5 & 36.4 & 42.3 & 0.1 & 3.3 & 1.4 & 1.9 \\
\hline & \multicolumn{9}{|c|}{ Fatty acid composition (\%) in FFA fraction ${ }^{(a)}$} \\
\hline & $16: 0$ & 18:0 & $18: 1$ & $18: 2$ & $18: 3$ & 20:0 & $20: 1$ & $24: 0$ & $\begin{array}{c}\text { Enrichment } \\
\text { of GLA }\end{array}$ \\
\hline \multicolumn{10}{|c|}{ Native lipases $^{(b)}$} \\
\hline Aspergilus niger & 14.4 & 4.9 & 19.9 & 35.8 & 16.5 & 0.9 & 5.7 & 1.9 & --- \\
\hline Fusarium oxysporum & 15.9 & 6.5 & 19.1 & 35.3 & 14.7 & 0.9 & 5.5 & 2.1 & --- \\
\hline Geotrichum candidum & 19.2 & 8.3 & 17.8 & 32.8 & 13.7 & 0.8 & 5.9 & 1.5 & --- \\
\hline Penicillium. solitum & 8.0 & 3.4 & 18.3 & 37.9 & 25.8 & 0.5 & 4.4 & 1.7 & 1.2 \\
\hline Rhizopus. japonicus & 14.2 & 5.8 & 17.9 & 35.4 & 20.6 & 0.6 & 4.2 & 1.3 & --- \\
\hline \multicolumn{10}{|c|}{ Commercial lipases } \\
\hline Aspergillus niger & 14.7 & 6.3 & 19.0 & 33.2 & 19.3 & 0.5 & 4.5 & 2.5 & --- \\
\hline Candida cylindracea & 18.4 & 7.6 & 20.3 & 33.6 & 11.4 & 0.8 & 5.7 & 2.2 & --- \\
\hline
\end{tabular}


The selective hydrolysis of borage oil with $C$. cylindracea (commercial) and G. candidum (native) lipases led to an significant increase in the GLA content from $21.5 \%$ in the original oil to approximately $40 \%$ in the unhydrolysed acylglycerols (1.8 - 1.9-fold enrichment). It is also evident that the GLA enrichment was accompanied by a decrease in the levels of palmitic (16:0), stearic (18:0) and a moderate decrease of oleic acid (18:1) in the unhydrolysed acylglycerols. For both lipases, linolenic acid (18:2) and GLA (18:3) were detected in the acylglycerols fraction in higher quantities, in comparison to the fraction of FFA, showing its preferentially release of saturated fatty acids from borage oil.

Hydrolysis with $A$. niger (commercial and native) and $F$. oxysporum lipases also enriched GLA in the unhydrolysed acylglycerols (1.4 - 1.5-fold enrichment); however, these lipases were not as effective as C. cylindracea and $G$. candidum lipases. On the other hand, $P$. solitum and $R$. javanicus lipases did not increase in the GLA contents in the unhydrolysed acylglycerols. As shown in Figure 1, the hydrolysis by the last two lipases was almost the same (approximately $12 \%$ of FFA released). However, the fraction containing FFA obtained by $P$. solitum lipase-mediated hydrolysis showed a high content of unsaturated fatty acids (86\%), obtaining a 1.2-fold enrichment of GLA. All other lipases showed selectivity to saturated fatty acids and preferentially released saturated fatty acids.

The ability of the lipase from commercial C. cylindracea to enrich GLA by selective hydrolysis of evening primrose and borage seed oil was previously reported (27). Many other reports confirm that $C$. cylindracea lipase is the most effective for concentrating other PUFAs in glyceride, such as arachidonic acid in oil extracted from Mortierella (22) and DHA in fish oil $(28,29)$. In this study, good results were also obtained with native $G$. candidum lipase (1.8-fold enrichment) used as biocatalyst for borage oil hydrolysis in the unhydrolysed acylglycerols fraction.

Figure 2 shows that the maximum enrichment of the GLA in the acylglycerols fraction occurs at between 20 and 24 hours of reaction, when catalyzed by native G. candidum lipase. Under these conditions, an enrichment of 39.5\% of GLA was achieved when the extract produced in SmF was used as a biocatalyst of the reaction. In this time, only $13.7 \%$ of GLA was found in the FFA fraction. A further increase in reaction time leads to a decrease in the extent of enrichment of GLA. In general, lipase yields obtained for G. candidum cultured in $500 \mathrm{~mL}$ flasks in $\mathrm{SmF}$ were similar to those obtained in 21 flasks (data not shown). When the extract produced in SSF underwent the same procedure, a maximum of $28 \%$ of GLA was found after $24 \mathrm{~h}$ of reaction.

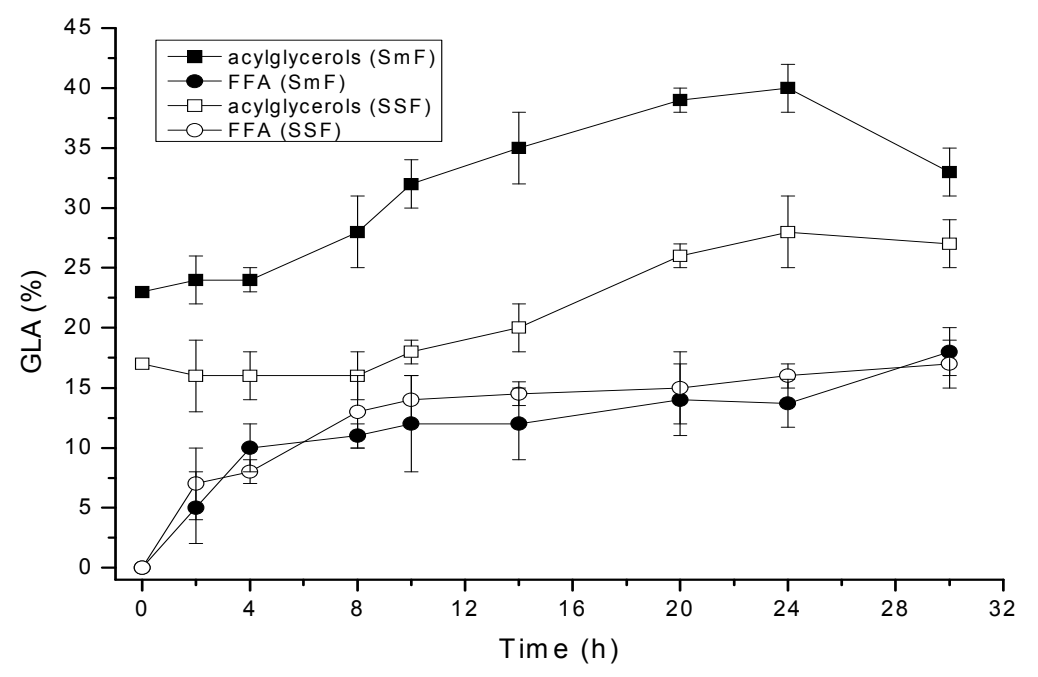

Figure 2. Change in GLA content in the acylglycerols (TG, DG and MG) and FFA fractions during the course of hydrolysis of borage oil, catalyzed by native $G$. candidum lipase produced in two different growing media. Reaction conditions are described in Materials and Methods 
This study shows also the effect of culture medium composition on the ability of the G. candidum lipase to enrich GLA. The different activity and optimal fermentation conditions of the substrates could be explained by the different digestibility of these carbon sources. However, activity and specificity studies of crude extracts can be complicated by the presence of more than one lipase. Some differences in the substrate specificity of various strains were observed, suggesting that the differences between the crude lipases could originate from either different isoforms or, more likely, from different ratios of these isoforms in various preparations (24). Although many studies show than $G$. candidum lipase features specificity towards fatty acids with a cis double bond at C9 (14), subsequent attempts to purify and identify lipases from Geotrichum strains resulted in contradictory reports regarding their substrate specificity (24, 1, 26). Different forms of Geotrichum sp lipases were identified and described as differing in substrate specificities. Two forms (I and II) of this lipase show non-positional specificity, while the other two remaining forms (III and IV) showed unusual positional specificity; they cleaved the inside (2-position) ester bond of triolein at nearly twice the rate of the cleavage at the 1 (3)-position (26).

The use of crude lipase preparations from G. candidum for the enrichment of GLA in glycerides by hydrolysis of blackcurrant oil was recently reported (25). This recent study shows the effect of culture medium composition on the isoenzyme pattern of the lipases produced by selected strains of Geotrichum sp. The enzymes from G. candidum produced in Medium A (urea, olive oil and minerals) preferentially released unsaturated fatty acids from blackcurrant oil triacylglycerols, as well as extracellular lipases from $G$. ludwiggi and G. candidum produced in Medium B (peptone, glucose, olive oil and minerals). On the other hand, a higher content of unsaturated fatty acids was found in the acylclycerols fraction (TG, DG and $\mathrm{MG}$ ) obtained from the hydrolysis of blackcurrant oil by extracellular lipase from $G$. ludwiggi induced in Medium A.
To decide on the optimal proportion between the amount of $G$. candidum lipase and borage oil content, the reaction was carried out for $24 \mathrm{~h}$ with 104.7 - $388.8 \mathrm{U} / \mathrm{g}$ of oil, as shown in Table 3. By increasing the content of the borage oil and, principally, increasing the concentration of the $G$. candidum enzyme, a higher enrichment of GLA was obtained in the acylglycerols fraction ( $\sim 42 \%$ of total fatty acid).

Table 3. Effect of the ratio of oil and enzyme on the enrichment of GLA in the acylglycerols and FFA fractions after $24 \mathrm{~h}$ of hydrolysis at $30^{\circ} \mathrm{C}$ with Geotrichum candidum lipase

\begin{tabular}{|c|c|c|}
\hline Lipase (U/g oil) & GLA (\% tota & cids) \\
\hline & Acylglycerols & FFA \\
\hline $104.7^{\mathrm{d}}$ & 35.2 & 15.4 \\
\hline $300.0^{\mathrm{a}}$ & 39.5 & 13.7 \\
\hline $317.8^{\mathrm{b}}$ & 41.7 & 14.6 \\
\hline $388.8^{\mathrm{c}}$ & 40.2 & 14.9 \\
\hline
\end{tabular}

Figure 2 and Table 3 demonstrate that the concentration of GLA in the FFA fractions does not present great changes, with its concentration remaining at around $15 \%$. Values of above $40 \%$ for the enrichment of GLA were obtained following catalysis by native $G$. candidum lipase, in accordance to the data reported in the literature for commercial lipases. The use of commercial C rugosa lipase resulted a $46 \%$ GLA-containing oil, by carrying out the hydrolysis of borage oil (GLA content, $22 \%$ ) at $35^{\circ} \mathrm{C}$ for $15 \mathrm{~h}$ in a solvent-free system (23). A maximum GLA content of $51.7 \%$ in the unhydrolyzed acylglycerols was reported in the hydrolysis of borage oil (GLA content, $23.6 \%$ ) with immobilized Candida rugosa lipase in isooctane at $30^{\circ} \mathrm{C}(13)$. 


\section{ACKNOWLEDGEMENTS}

This study was supported by Fundação de Amparo à Pesquisa do Estado de São Paulo of Brasil. The authors thank the Centro de Micologia da Universidade de Lisboa (Portugal) and Novozymes Latin America Ltda (Brasil).

\section{REFERENCES}

1. Asahara, T.; Matori, M.; Ikemoto, M.; Ota, Y. (1993). Production of two types of lipases with opposite positional specificity by Geotrichum sp FO 401B. Biosci Biotechnol Biochem 57:390-394

2. Budeiri D, Li Wan PA, Dornan CJ (1996) Is evening primrose oil of value in the treatment of premenstrual syndrome? Control Clin Trials 17: $60-68$.

3. Cai, J.; Jiang, W.G.; Mansel, R.E. (1999). Inhibition of angiogenic factor- and tumour-induced angiogenesis by gamma linolenic acid. Prostaglandins Leukot Essent Fatty Acids 60:21-29.

4. Carvalho, P.O.; Pastore, G.M. (1998). Enrichment of GammaLinolenic acid from fungal oil by lipases. Food Biotechnol 12:57-71.

5. Carvalho, P.O.; Campos, P.R.B.; Bastos, D.H.M.; Oliveira, J.G. et al (2002). Enzymic Enhancement of $\omega 3$ Polyunsaturated Fatty Acids Content in Brazilian Sardine Oil. Acta Farm Bonaerense 21: 85-88.

6. Carvalho, P.O.; Campos, P.R.B.; Noffs, M.D.; Oliveira, J.G. et al (2003). Aplicações de lipases microbianas na obtenção de concentrados de ácidos graxos poliinsaturados. Quim Nova 26:75-80.

7. Chawla, P.; DeMan, J.M. (1990). Measurement of the Size Distribution of Fat Crystals Using a Laser Particle Counter. J Am Oil Chem Soc 67:329-332

8. Domsch, K.H.; Gams, W.; Anderson, T.H. (1993). Compendium of Soil Fungi v1 Eching, IHV-Verlag, Germany.

9. Dos Prazeres, J.N.; Cruz, J.A.B.; Pastore, G.M. (2006). Characterization of alkaline lipase from Fusarium oxysporum and the effect of different surfactants and detergents on the enzyme activity. Braz J Microbiol 37:505-509.

10. Dokholyan, S.R.; Albert, C.M.; Appel, J.L.; Cook, R.N. et al. (2003). A Trial of Omega-3 Fatty Acids for Prevention of Hypertension. Am J Cardiol 93:1041-1043.

11. Eriksen, B.B.; Kare, L.D. (2006). Open trial of supplements of omega 3 and 6 fatty acids, vitamins and minerals in atopic dermatitis. $J$ Derm Treat 17:82-85.

12. Hoshino, T.; Sasaki, T.; Watanabe, Y.; Nagasawa, T. et al. Purification and some characteristics extracellular lipase from Fusarium oxysporum f sp Lini. Biosci Biotechnol Biochem 56:660-664.
13. Huang, F.C.; Ju, Y.H.; Huang, C.W. (1997). Enrichment of $\gamma$-Linolenic Acid from Borage Oil via Lipase-Catalyzed Reactions. J Am Oil Chem Soc 74:569-573.

14. Jensen, R.G. (1983). Detection and determination of lipase (acylglycerol hydrolase) activity from various sources. Lipids 18:650657.

15. Mase, T.; Matsumiya, Y.; Akiba, T. (1995). Purification and characterization of a new lipase from Fusarium SP YM-30. Biosci Biotechnol Biochem 59:1771-72.

16. Nakayama, K. (1981). Sources of industrial microorganisms. In: Rehm HJ, Reed G (ed) Biotechnology VCH Verlag, Veinheim, vol 1, pp $355-$ 410.

17. Okada, T.; Morrissey, M.T. (2007). Production of n-3 polyunsaturated fatty acid concentrate from sardine oil by lipase-catalyzed hydrolysis. Food Chem 103:1411-1419.

18. Pejic, N.R.; Lee, T.D. (2006). Hypertriglyceridemia. J Am Board Fam Med 19:310-316.

19. Ratnayake, W.M.N.; Olsson, B.; Matthews, D.; Ackman, R.G. (1988). Preparation of Omega-3 PUFA Concentrates from Fish Oils via Urea Complexation. Wood Sci Technol 90:381-386.

20. Saxena, R.K.; Ghosh, P.K.; Gupta, R.; Sheba Davidson, W.S.; Bradoo, S.; Gulati, R. (1999). Microbial lipases potential biocatalysts for the future industry. Curr Sci 77:101-115.

21. Shimada, Y.; Maruyama, K.; Okazaki, S.; Nakamura, M. et al. (1994) Enrichment of polyunsaturated fatty acids with Geotrichum candidum lipase. J Am Oil Chem Soc 71:951-954.

22. Shimada, Y.; Sugihara, A.; Maruyama, K.; Nagao, T. et al. (1995) Enrichment of arachidonic acids: selective hydrolysis of a single-cell oil from Mortierella with Candida cylindracea lipase. J Am Oil Chem Soc 72:1323-1327.

23. Shimada, Y.; Fukushima, N.; Fugita, H.; Honda, Y. et al. (1998). Selective Hydrolysis of Borage Oil with Candida rugosa Lipase: Two Factors Affecting the Reaction. J Am Oil Chem Soc 75:1581-1586.

24. Sidebottom, C.M.; Charton, E.; Dunn, P.P.; Mycock, G. et al. (1991). Geotrichum candidum produces several lipases with markedly different substrate specificities. Eur J Biochem 202:485-491.

25. Stránský, K.; Zarevúcka, M.; Kejík, Z.; Wimmer, Z. et al. (2007). Substrate specificity, regioselectivity and hydrolytic activity of lipases activated from Geotrichum sp. Biochem Eng J 34:209-216.

26. Sugihara, A.; Shimada, Y.; Nakamura, M.; Nagao, T. et al. (1994). Positional and fatty acid specificities of Geotichum candidum. Protein Eng 7:585-588.

27. Syed Rahmatullah, M.S.K.; Schukla, V.K.S.; Mukhergee, K.D. (1994). Enrichment of $\gamma$-Linolenic Acid from Evening Primrose Oil and Borage Oil via Lipase-Catalyzed Hydrolysis. $\mathrm{J}$ Am Oil Chem Soc 71:569-573. 
Fregolente, P.B.L. et al.

28. Tanaka, Y.; Hirano, J.; Funada, T. (1992). Concentratiom of docosahexaenoic acid in glyceride by hydrolysis of fish oil with Candida cylindracea lipase. J Am Oil Chem Soc 69:1210-1214.

29. Tanaka, Y.; Funada, T.; Hirano, J.; Hashizume, R. (1993). Triglyceride specificity of Candida cylindracea: Effect of docosahexaenoic acid on resistance of triglyceride to lipase. J Am Oil Chem Soc 70:1031-1034.

30. Walker, R.O. (1978). Official and Tentative of the American Oil Chemists' Society - Method Ce 2-66, American Oil Chemists' Society, 3rd ed, Champaign.

31. Wille, H.J.; Wang, J. (1996). Enzymatic enrichment of $\gamma$-Linolenic acid from blackcurrant seed oil. In: Huang YS, Mills DE (ed) $\gamma$-Linolenic, metabolism and its roles in nutrition and medicine, AOCS Press, Champaign, pp 33-41.

32. Yin, J.Z.; Wang, A.Q.; Wei, W.; Liu, Y. et al. (2005). Analysis of the Operation Conditions for Supercritical Fluid Extraction of Seed Oil. Sep Purif Technol 43:163-167. 